\title{
Effectiveness of Automation in Evaluating Test Results Using EvalBee as an Alternative Optical Mark Recognition (OMR): A Quantitative-Evaluative Approach from a Philippine Public School
}

\author{
Ronnel P. Cuerdo1, Michael Jomar B. Ison'1, Christian Diols T. Oñate1 \\ 1 Pamantasan ng Cabuyao, Laguna State Polytechnic University, Philippines
}

\begin{abstract}
Within this study, the authors want to address the problem of overworking of teachers in Philippine schools due to their excessive clerical responsibility, which could lead to teacher attrition. The authors propose to automate the process, particularly the evaluation of student test results since it could improve human wellbeing by reducing the burden of manual labor. Automation using OMR has not been widely applied in Philippine schools due to cost issues. The authors want to observe whether an alternative OMR - EvalBee - can meet the evaluation standard even though it is free of charge. The study employed a quantitative-evaluative research method. Validated questionnaires on paper and a Google Form survey were used to collect relevant data in a secondary public school in the City Schools Division of Cabuyao - Southville1 Integrated National High School. Statistical tools such as the mean, standard deviation, t-test, and Cohen's d were used in this research to determine the effectiveness of using alternative OMR in evaluating examinations. This study shows that alternative OMR is efficient, accurate, and reliable, despite the fact that it is free, and recommends it be used as part of the teachers' standard method of test evaluation.
\end{abstract}

Keywords: alternative optical mark recognition, integrating automation, student test evaluation, automated checking, automated item analysis

\section{(c) (1) (9) \\ This is an open-access article under the CC-BY-NC license.}

\section{INTRODUCTION}

Education is an abstract word. For the educators, to implement their profession requires a definite procedure of measurement to establish the effectiveness and efficiency of the educative process. It cannot be overemphasized those specific types of procedures are necessary to institute a measurement index of development in every student and/or the educative process as a whole.

One of the most critical components of school assessments, if not the most critical component, is student test results. These test results not only serve as a means of monitoring the progress of students but also serve as an index of how the teacher is making progress themselves. It cannot be overstressed that these data must be processed under utmost care and conscientiousness [1]. Manually processing student test results is tiresome, requires so much time, and is vulnerable to errors, especially when a significant number of students are involved [2]. The teachers in charge of student test results processing are not only burdened with marking exams, but with a lot of other academic work, like lecturing, research, and attending to some administrative tasks. Given that these processes must be conducted out in a constant cycle, that and other responsibilities have a detrimental effect on the teachers' quality of life [3].

According to the literature on student test result processing, almost all public schools under the Department of Education still engage in manual processing of test results. The slow integration of automation can be attributed to several factors, including the elevated cost of purchase, servicing, and support [2]. Meanwhile, applied science or technology tends to promote human well-being by lessening the burden of manual work. Otherwise called automation, it is the process of developing and deploying technologies with the least human intervention. Automation systems, techniques, and processes improve the efficiency, 
International Journal of Theory and Application in Elementary and Secondary School Education (IJTAESE), Vol. 3 (2), 61-75

Effectiveness of Automation in Evaluating Test Results Using EvalBee as an Alternative Optical Mark Recognition

(OMR): A Quantitative-Evaluative Approach from a Philippine Public School

Ronnel P. Cuerdo, Michael Jomar B. Ison, Christian Diols T. Oñate

accuracy, and reliability of a variety of previously performed human activities. It is now used in a variety of fields, including manufacturing, transportation, services, and so on [4].

Automated electronic processing of test results is not new. It is utilized in almost all national standardized testing conducted by the national government in public and private schools, such as the National Achievement Test (NAT), National Career Assessment Exam (NCAE), Basic Education Exit Assessment (BEEA), and others [5]. There are certain efforts to automate the processing of test results at the local level. For instance, the City Schools Division of Santa Rosa City has obtained an OMR Reader [6]. It was in line, according to the same author, with their commitment to utilizing information communications technology. Another brave initiative to implement the same automation came from the Division of Batangas City. In 2015, the Division of Batangas City purchased ten (10) OMR machines worth nearly twelve (12) million pesos thru their connections with the local government [7]. According to the same author, the action was in line with the advocacy of the Department of Education towards a shared understanding of the purposes of quality teaching, learning, and objective evaluation.

OMR is a procedure that collects data by identifying marks on paper. OMR is accomplished by detecting a reflection or a limited amount of light using a hardware device [8]. OMR readers or scanners are typically used to scan forms/sheets where an examinee will use a pencil or ballpen to shade in a circle or other geometric shape on a form to answer a question. It can also be used to provide data solutions such as testing and surveys where results, analysis based on visual presentations such as graphs, tables, and other illustrations can automatically be derived. While optical mark reader machines are highly efficient for automatically scoring hand-marked answers, a great number of literatures confirmed that they are generally expensive to acquire and operate [8]-[12].

Thus, education as a process requires a definite amount of measurement, which should be reliable and accurate. Systematically, teachers for hundreds of years achieved the requirement using the time and tested method of manually processing every student output. On the other hand, the present era of science and technology tends to promote human well-being by lessening the burden of manual work. The process of education is no solid wall.

The literature on OMR machines, on the other hand, has produced positive results and favorable recommendations. However, the obvious disadvantage is that OMR machines are quite expensive. It was also confirmed as clearly stated in the studies of Patel and Prajapati (2015), Karunanayake (2015), Tavana et al. (2016), Kakade and Jaiswal (2017), and Catalan (2017) that OMR machines are expensive to attain and maintain. To make something out of it, an alternative is necessary. An alternative that will qualify for such benefits but does not have any disadvantages.

Meanwhile, as of 2019, there were roughly 74 million smartphone owners in the Philippines out of the national population of 104 million Filipino. By the year 2025, it is expected that there will be approximately 90 million smartphone owners [13]. Smartphones can provide a much better and cheaper alternative in integrating automation into the processing of the test results of students. The digital cameras of smartphones coupled with image processing software offer this cheaper alternative [8]. As an alternative, it should not only satisfy the necessity for a cheaper alternative but also provide functionality within the bounds of standard quality.

The Google Play Store offers plenty of free downloadable software for alternative OMR. These alternative OMR applications are designed to help teachers design and generate instant exam reports by scanning answer sheets with a phone camera. This study specifically used EvalBee by Ekodroid Labs, which can be acquired for free through the Google Play Store [14]. Thus, there is a significant dearth of studies in the Philippines in applying automation in the education sector. Another point of emphasis is the significant lack of study on the use of optical mark recognition machines in exam evaluation. Furthermore, existing research suggests the usage of relatively expensive technology, which could be the primary reason why it has not been implemented in Philippine schools.

The findings of this study could become the basis for a new policy of integrating automation using alternative Optical Mark Recognition in evaluating examinations in public schools. It would significantly 
International Journal of Theory and Application in Elementary and Secondary School Education (IJTAESE), Vol. 3 (2), 61-75

Effectiveness of Automation in Evaluating Test Results Using EvalBee as an Alternative Optical Mark Recognition

(OMR): A Quantitative-Evaluative Approach from a Philippine Public School

Ronnel P. Cuerdo, Michael Jomar B. Ison, Christian Diols T. Oñate

reduce teachers' time-consuming tasks of checking, evaluating, and analyzing students' regular assessment results.

\section{Statement of The Problem}

The efficiency of integrating automation in evaluating student test results using alternative Optical Mark Recognition in a public school was investigated in this study. Specifically, it sought to answer the following questions:

1. What is the level of efficiency using manual vis-à-vis alternative OMR procedures in checking test papers and analyzing its results?

2. What is the level of reliability of data output using manual and alternative OMR procedures in checking test papers and analyzing its results?

3. What is the level of accuracy of data output using manual and alternative OMR procedures in checking test papers and analyzing its results?

4. Is there a significant difference between the level of efficiency using manual and alternative OMR procedures?

5. Is there a significant difference between the level of accuracy and reliability of data output using manual and alternative OMR procedures?

6. Is there a significant difference between the level of reliability of data output using manual and alternative OMR procedures?

\section{Objectives of The Study}

This study centered on determining quality standards by measuring the effectiveness of the alternative OMR. The study determines how efficient, accurate and reliable this process in item checking and analyzing the student's test results. In other words, it centered on evaluating an alternative OMR that not only satisfies the necessity for a cheaper alternative but also provides functionality within the bounds of standard quality to qualify as a better alternative.

\section{LITERATURE REVIEW}

The pervading thread in this literature review was based on the theoretical assumptions that technological advancement has aided and continues to aid humans in the continuing struggle to realize a better future and that automation systems, techniques, and processes improve the efficiency, accuracy, and reliability of a variety of previously performed human activities. It assumes, moreover, that technology has been the primary means through which humankind will be able to solve social issues. In the immediate sense, technology has been the primary means through which the burden of clerical work among teachers will be solved. These assumptions, among others, were associated with Technological Determinism.

According to Spencer (2016), the terminology was introduced by American writer and economist Thorstein Veblen. In the 1900s, another very dynamic technological determinist in the United States was Clarence Ayres, a proponent of the Texas school of Institutional Economics and adherent of John Dewey and Thorstein Veblen. Technological determinism assumes that economic, political, and cultural aspects of society at large are inextricably linked to the progression of technology. In the eighteenth and nineteenth centuries, a significant development occurred in the fields of life and social sciences and rising participation in secularism. This combination of factors fueled technological determinism. The claim is that technological advances are fundamentally unavoidable [15].

The first major development of Technological Determinism as a theory was proposed by the German philosopher, economist, and communist, Karl Heinrich Marx. Contemporary society has accepted the belief that continually advancing technology profoundly affects the way people live, and Marx's position was deeply rooted in that belief. Karl Marx claims that, above all, technological developments, especially those that facilitate production, have the most profound impact on human social interactions and organization structures and those social interactions and cultural practices are 
International Journal of Theory and Application in Elementary and Secondary School Education (IJTAESE), Vol. 3 (2), 61-75

Effectiveness of Automation in Evaluating Test Results Using EvalBee as an Alternative Optical Mark Recognition

(OMR): A Quantitative-Evaluative Approach from a Philippine Public School

Ronnel P. Cuerdo, Michael Jomar B. Ison, Christian Diols T. Oñate

ultimately determined by the socioeconomic and technological framework of a particular society. And Marx's prediction that the accelerating pace of technological advancement would have an impact on daily life has been proven correct. There are those who see technological determinism at the core of Marx's theory. There are a number of different technological determinisms as well [16].

With the advent of modern versions of technological determinism, the whole mechanistic perspective has been weakened marginally [17]. Techno optimism presents itself as one of the variants of the technological determinism of the eighteenth and nineteenth centuries. The incredibly strong techno-optimist perspective, which maintains that technological progress is almost historically inescapable, stresses the connection between techno-optimism and technological determinism, including the multiple approaches and interpretations that result from it [15].

Techno-optimism is one of the two contrasting viewpoints on the advantages and disadvantages of technological progress. The core beliefs of techno-optimism are that the overall trajectory of technical growth is accurate and positive, that the benefits of technology exceed the disadvantages, and that current or prior developments will be addressed by technology itself. Techno-optimism, defined directly, is the doctrine that a growing number of technological improvements will sustain and improve human life [18], [19].

The theoretical framework of this research relied mainly on the work of Matthewman (2016), specifically his book. This book is about the difference between technological determinism and social context interpretation. It is the central and animating issue of Steve Matthewman's writing. For example, it emphasized the importance of technology in explaining social occurrences in society on the one hand and the importance of technology in society on the other. Social explanations of technology pervade many of the book's fascinating discussions. This book's first four chapters introduce and contextualize the work of Karl Marx and Walter Benjamin in the traditional sociological context, as well as the work of Michel Foucault and Langdon Winner. As an example of technological determinism, Matthewman cites Karl Marx's oft-quoted statement that "the hand-mill brings you society with the feudal lord; the steam mill brings you society with the commercial capitalist."

Meanwhile, it is common knowledge that teachers oversee educating and training students to attain their educational objectives. However, the work of a teacher is more complicated nowadays. In addition to teaching, teachers are frequently tasked with clerical jobs such as being a presenter, promoter, organizer, instructional consultant or organization manager, athletic directors, student data analytics, classroom behavior manager, and a variety of other responsibilities.

Nurwahida et al. (2017), highlights the critical concerns concerning the competence of teachers that directly influence the quality of education. They went on to say that skilled teachers are expected to successfully combine expertise with educational approaches to clearly communicate ideas to students. Teachers must plan teaching methodologies to present successful learning, but they are now explicitly delegated with increased clerical tasks such as introducing new or changing student information, collecting fees, supplying textbooks, reviewing logbooks, analyzing the student qualification for financial assistance, as well as other paperwork. Much of the work is done by hand, and they are more likely to spend more time on paper works rather than focusing on an instructional way to enhance education quality [20].

Cabigas (2019) addressed the K-12 Program in the Philippines. He has investigated the initiated systematic overhaul of the Philippines education system to resolve the problem of the deteriorating standard of Philippine education. With the recent implementation of these reforms, the government estimated that more than sixty- thousand teachers would be required to accommodate the present needs. A year after its introduction, however, it was revealed that the number of teachers leaving the profession has actually increased, instead of more people entering the teaching profession amid high demand for teachers. In the Philippines, as indicated in the reports of the Philippine Statistics Authority (PSA, 2020), the country is constantly losing teachers. According to Cabigas (2019), also citing the PSA, 
International Journal of Theory and Application in Elementary and Secondary School Education (IJTAESE), Vol. 3 (2), 61-75

Effectiveness of Automation in Evaluating Test Results Using EvalBee as an Alternative Optical Mark Recognition

(OMR): A Quantitative-Evaluative Approach from a Philippine Public School

Ronnel P. Cuerdo, Michael Jomar B. Ison, Christian Diols T. Oñate

the country experiences a significant loss of 132 individuals annually, indicating that far more teachers are leaving the teaching career than joining it [21].

The ensuing product is burnout which leads to Teacher Attrition, according to Jacobson (2016).

Teacher burnout is not a new phenomenon, but teacher burnout is rising with increasing frequency.

Teacher burnout is a concern causing school burnout, owing to the financial and academic toll it has on education districts nationwide [22].

The above phenomenon, known as Teacher Attrition (TA), was the subject of research done by Oke, Ajagbe, Ogbari, \& Adeyeye (2016). They describe it as the declining number of teachers in the field of education due to a number of reasons. Several studies have concentrated on the attrition of teachers, citing its various effects on not only education. The achievements of the students, as well as the country's academic achievements, were negatively affected. The author also reiterated that educational quality suffered as a growing number of teachers quit the profession, unable to build a collaborative relationship that may have aided teachers to enhance training, recruiting, and professional growth [23].

A variety of factors influence teachers' choice to abandon an academic career, including excessive workload, learner misconduct, seclusion, and so on. In addition to the standard full-time teaching load required by the Magna Carta for Public School Teachers, each teacher is required to perform some added administrative functions or learner support services as part of their job description. Activities other than teaching include attending seminars and training, decorating classrooms, and participating in various public services such as mass vaccinations, community surveying, conditional cash transfers, feeding programs, demographic censuses, anti-drug election campaigns, among others. Teachers in the Philippines are constantly overburdened by this problem. Such positions restrict the amount of time available for actual teaching tasks, which has a significant effect on the overall quality of Philippine education [24].

The Philippine government itself, through the Philippine Institute for Developmental Studies (2015), confirmed that low salaries, workload, and excessive hours of work are among the reasons for this phenomenon [25]. The Department of Education itself has recognized that, indeed, teachers are overloaded and are continually making efforts to alleviate such. A statement issued by the Department of Education (DepEd) in 2018 stated that it was considering initiatives such as the potential formation of new non-teaching items for other clerical works. To keep teachers more resilient, DepEd also tells them that a teaching career is one of the noblest and rewarding calls to which one can dedicate oneself, adding that it takes double the zeal and devotion to be in public service [26].

In the meantime, De Witte (2019) said, among others, that the area of assistive technology or automated technology worldwide, as well as at the national levels, is attracting more and more attention. He also believed that technology could be a powerful instrument that helps people to live an enjoyable life [27]. Li and Wong (2018), on the other hand, have explicitly indicated that the teaching and learning process has become increasingly difficult. The inconsistency can be felt immediately. On the one hand, automation is making human life much easier and enjoyable. On the other hand, the teaching and learning process is becoming more difficult. Thus, automation is quickly becoming a necessity in the field of education [28].

Optical Mark Recognition was introduced in the early 1930s as part of the automation process, according to Patel and Prajapati (2015). It is defined as the scanning method for either the presence or absence of a mark on a page in a specific area. It gathers human-marked data such as surveys and assessments from document forms. OMR is used to read questionnaires, multiple-choice test papers with lines or shaded areas, election returns, and other documents. It began with Richard Warren, a former IBM employee who experimented with the optical mark-sense system [9].

The educational environment in the Philippines, in terms of OMR, has only recently begun its course. The study of Catalan (2017) establishes a methodology for various exam that is using computer images and various processing techniques. According to the same author, OMR is commonly used in a 
International Journal of Theory and Application in Elementary and Secondary School Education (IJTAESE), Vol. 3 (2), 61-75

Effectiveness of Automation in Evaluating Test Results Using EvalBee as an Alternative Optical Mark Recognition

(OMR): A Quantitative-Evaluative Approach from a Philippine Public School

Ronnel P. Cuerdo, Michael Jomar B. Ison, Christian Diols T. Oñate

variety of applications, including examination assessment, automatic attendance marking, voting, and group surveys, among others. However, these devices can be extremely expensive to purchase and operate [8].

The study conducted by Dr. Lilibeth M. Virtus (2019) in Batangas City's school division was another brave initiative to implement the same automation, which gave highly favorable conclusions and recommendations on the use of OMR. According to the same author, the action was in line with the advocacy of the Department of Education towards a shared understanding of the purposes of quality teaching, learning, and objective evaluation. It has become necessary to investigate the effectiveness of automation in evaluating examinations using alternative OMR [7].

The study of Karunanayake (2015), Tavana et al., (2016) and Kakade (2017) presents an alternative OMR using low-cost web camera. Based on these studies, the sheet evaluation system achieved an accuracy of 97.6 percent, 99.85 percent and 88 percent respectively. Although these studies used relatively less expensive equipment than an OMR machine, these processes were not portable and required additional computer hardware and software to operate [10]-[12].

The study of Patel and Prajapati (2015) and Patoule et al. (2016) offered a novel technique or alternative OMR for grading multiple-choice tests. It required a system that used a computer, a scanner, and a program-based application. The findings showed that the suggested method is not only dynamic and economical but also effective at multiple configurations. These investigations made use of technology that was less costly than an OMR machine. Nevertheless, the utilized procedures were not portable and needed additional computer hardware and specialized software in order to be carried out [9], [32].

The study of Capunitan et al. (2019) conducted in Calamba's school division was very instructive in checking and evaluating student responses. It used portable device and a software application. The goal was to ensure the consistency and validity of the integrated evaluation data and to provide satisfactory answers. The study indicated the significance of new technology and the need for teachers to learn and apply the same to their work. Recommendations were also made to formulate the local policy on digital assessment and the need to enforce it. Even though the study used an alternative type of OMR using a portable device, it required an expensive premium software application to operate [29].

In the meantime, as has been established in a large body of literature, teachers are overworked. The Department of Education (DepEd), moreover, has recognized that, indeed, teachers are overloaded and are continually making efforts to alleviate such an issue. DepEd is considering initiatives such as discussions with teachers about data sharing rather than generating various forms, as well as the possibility of new non-teaching items for the necessary preparation of administrative and management reports, all of which would help alleviate overburdened teachers [26].

Those efforts are not enough. As Techno-optimism has suggested, a steady advancement in applied science or technology aimed at improving human well-being by reducing the load of manual labor, or the development and deployment of technology to generate and distribute things and services with minimum human input, has become necessary. Applied automation has become a necessity.

On the one hand, OMR researchers concluded, among other things, that the OMR machines and another alternative type of OMR were effective in processing student test results and providing rapid and accurate evaluation results. Studies also highly recommended that teachers use OMR machines and another alternative type of OMR to scan student test results, among other things, due to their efficacy in automatically scoring hand-marked responses as well as their quick and precise evaluation findings. On the other hand, the disadvantage is that OMR equipment is very costly to acquire and maintain. It will take an alternative to make something out of it. An alternative that qualifies for such benefits but does not have any disadvantages. An alternative which not only meet the need for an inexpensive alternative but should also provide functionality within the bounds of standard quality. 
International Journal of Theory and Application in Elementary and Secondary School Education (IJTAESE), Vol. 3 (2), 61-75

Effectiveness of Automation in Evaluating Test Results Using EvalBee as an Alternative Optical Mark Recognition

(OMR): A Quantitative-Evaluative Approach from a Philippine Public School

Ronnel P. Cuerdo, Michael Jomar B. Ison, Christian Diols T. Oñate

The peculiar contribution of this paper, which to the knowledge of the author, was not done anywhere, is to fill a humble gap in the Philippines literature regarding the use of optical mark recognition in evaluating student test results, particularly alternative OMR. A portable process that can meet the evaluation standard even though it is free of charge. And by doing so, the researchers hope to make a small contribution toward relieving the teacher of the burden of excessive workload in the process.

\section{RESEARCH METHOD}

To effectively address the problem and to determine the effectiveness of automation using alternative Optical Mark Recognition in evaluating student test results in a public school, a descriptive-evaluative type of research design has been adopted.

Statistical tools such as the mean, standard deviation, $t$-test, and Cohen's $d$ were used in this research to determine the effectiveness of integrating automation using alternative Optical Mark Recognition in evaluating examinations. The result of the study led to determining the result of a data set that has a statistically significant level of effectiveness. The result of the study also led to determining how tightly all the various examples were clustered around the mean in a set of data. Cohen's $d$ was the final statistic used to determine the study's outcome, which assessed whether there was a statistically significant difference between the two-group means that could be attributed to such attributes, as well as whether the data sets were normally distributed and contained variability.

The research instrument that has been used is based on the operational definition of effectiveness, which is the tripartite level of measured efficiency, accuracy, and reliability of planned activities and results. In evaluating effectiveness, therefore, manual processing and alternative OMR processing of student test results have been subjected to evaluation according to efficiency, which is the ability to do something with the least amount of time, resources, and effort or performance expended, to the reliability, which is the consistency of measured output, and to accuracy, which is the state of being precise or correct or the capacity to skillfully do something without making mistakes.

\section{Research Procedure}

In order to conduct the research project, the researcher obtained permission from the principal of Southville1 Integrated National High School. The researcher has also secured the consent of the advisory teachers of the students, as per D.O. no. 40, s. 2012 [30], they can exercise parental authority. With the generous advice and assistance of the Principal and a Key Teacher in the same school, the researcher was able to conduct a face-to-face orientation specifically designed for the teacher-respondents on May 25, 2021. Included in this orientation were the process of downloading EvalBee from the Google Play site and the installation of said software on the smartphones of the teacher-respondents. A prepared PowerPoint presentation was also discussed for the teacher-respondents to properly utilize EvalBee software, the features of the software as well as the technical know-how to fill out a simple OMR sheet. The researcher personally delivered the orientation seminar to the respondents. Twenty-three-point-four percent (23.4\%) or twentyfive (25) out of one-hundred-seven (107) junior high school teachers of Southville1 Integrated National High School belonging to various levels volunteered to become the teacher-respondents.

In the administration of testing, the twenty-five (25) teacher-respondents conducted their scheduled test by giving the test questionnaires together with the answer sheets to the students. The answer sheet was designed to be answered on printed sheets through shading of small circles and to be read using alternative OMR. It was distributed to the students during the distribution/retrieval schedule for the week (every gradelevel was given one day each week) and was collected on the distribution/retrieval schedule the other week.

In the first stage of processing student test results, twenty (20) student test results were randomly selected by each teacher-respondent by randomly picking in the stacks of shuffled student test results (playing card method). The twenty randomly selected test results were marked with the numbers 1 to 20 on the back of the test results. It was scanned individually on the smartphones of the teachers' respondents using Alternative OMR. The student exam results, together with the automated item analysis results, were exported 
International Journal of Theory and Application in Elementary and Secondary School Education (IJTAESE), Vol. 3 (2), 61-75

Effectiveness of Automation in Evaluating Test Results Using EvalBee as an Alternative Optical Mark Recognition

(OMR): A Quantitative-Evaluative Approach from a Philippine Public School

Ronnel P. Cuerdo, Michael Jomar B. Ison, Christian Diols T. Oñate

as an Excel file for grade consolidation. For brevity's sake, stage one data output was termed OMR exam data 1. The time of scanning the test results up to the time of showing a no-error output has been monitored accordingly. The monitoring sheet, as well as the research instrument, were both ready for immediate data input.

For the second stage of processing, also called the comparison and double-checking, the accuracy and reliability of all the data output were tested by repeating the process done in the first stage. The only difference is that the data outputs of the first stage (OMR exam data 1) were compared and analyzed with the current data (OMR exam data 2) according to test accuracy and reliability of data based on output discrepancy and/or output errors. The monitoring sheet, as well as the research instrument, were both ready for immediate data input.

The same test results were subjected to manual processes of checking and item analysis. The data output from these processes was compared and analyzed with OMR exam data 2 to test for accuracy and reliability of the data based on output errors and discrepancy, respectively. The commencement of checking the test results using the manual process up to the time of finishing the item analysis output has been monitored accordingly. The monitoring sheet and, at the same time, the research instrument were always ready for immediate input of data. With the help of twenty-five (25) teacher- respondents, this research has subjected five hundred (500) test results in total in the span of three (3) weeks.

\section{FINDINGS AND DISCUSSION}

\section{Level of Efficiency in Checking Test Papers}

The results of the level of efficiency using manual vis-à-vis alternative OMR procedure in checking test papers and analyzing its results is shown in Table 1.

As shown in Table 1, the alternative OMR procedure is more efficient in checking test papers and analyzing its results with a mean score of $1.05(\mathrm{SD}=0.21$ ) compared to the manual procedure, which obtained a mean evaluation of $4.76(\mathrm{SD}=0.72$ ). It indicates that alternative OMR has a better ability to check and analyze test items with less amount of time, resources, and effort or performance consumed. Moreover, the table shows how extreme the difference is between alternative OMR and manual processes with respect to time and effort consumed, "very efficient" and "inefficient" respectively. According to Karunanayake (2015), the most evident benefit of employing OMR technology in the collection of data from documents is its efficiency when compared to the manual process, which is a time-consuming and tedious task [12].

Table 1. Level of efficiency of using manual vis-à-vis alternative OMR procedure in checking test papers and analyzing its results

\begin{tabular}{|l|l|l|l|c|}
\hline \multirow{2}{*}{ Activity } & Procedure & Mean & Std. Dev. & $\begin{array}{c}\text { Descriptive } \\
\text { Interpretation }\end{array}$ \\
\hline \multirow{2}{*}{$\begin{array}{l}\text { Checking } \\
\text { test papers }\end{array}$} & OMR & 1.05 & 0.21 & Very Efficient \\
\cline { 2 - 5 } $\begin{array}{l}\text { Analyzing } \\
\text { results }\end{array}$ & Manual & 4.76 & 0.72 & Inefficient \\
\cline { 2 - 5 } & Manual & 1.05 & 0.21 & Very Efficient \\
\hline
\end{tabular}

Legend: $1.00-1.49$ ( 1 min or less) = Very Efficient

$1.50-2.49(2 \mathrm{mins})=$ Efficient

$2.50-3.49$ (3 mins) $=$ Moderately Efficient

$3.50-4.49$ ( 4 mins) = Somewhat Inefficient

$4.50-5.00$ (more than 5 mins) = Efficient 
International Journal of Theory and Application in Elementary and Secondary School Education (IJTAESE), Vol. 3 (2), 61-75

Effectiveness of Automation in Evaluating Test Results Using EvalBee as an Alternative Optical Mark Recognition

(OMR): A Quantitative-Evaluative Approach from a Philippine Public School

Ronnel P. Cuerdo, Michael Jomar B. Ison, Christian Diols T. Oñate

\section{Level of Accuracy of Data Output}

The results of the level of accuracy of data output using manual and alternative OMR procedures in checking test papers and analyzing is shown in Table 2.

Table 2. Level of accuracy of using manual vis-à-vis alternative OMR procedure in checking test papers and analyzing its results

\begin{tabular}{|l|l|l|l|l|}
\hline \multirow{2}{*}{ Activity } & Procedure & Mean & Std. & $\begin{array}{l}\text { Descriptive } \\
\text { Interpretation }\end{array}$ \\
\hline \multirow{2}{*}{ Checking test papers } & OMR & 1.01 & 0.03 & Very Accurate \\
\cline { 2 - 5 } & Manual & 1.03 & 0.13 & Very Accurate \\
\hline \multirow{2}{*}{ Analyzing results } & OMR & 1.00 & 0.02 & Very Accurate \\
\cline { 2 - 5 } & Manual & 1.03 & 0.12 & Very Accurate \\
\hline
\end{tabular}

Legend: $1.00-1.49$ (1 $\mathrm{min}$ or less $)=$ Very Accurate

$1.50-2.49(2 \mathrm{mins})=$ Accurate

$2.50-3.49$ (3 mins) = Moderately Accurate

$3.50-4.49$ (4 mins) = Somewhat Inaccurate

$4.50-5.00$ (more than 5 mins) = Inaccurate

As presented in Table 2, both the alternative OMR and manual procedures produce very accurate results in checking test papers with a closer mean score of 1.01-1.03 (SD $=0.03-0.13$ ); also, both the alternative OMR and manual procedures produce very accurate results in analyzing test papers with a closer mean score of 1.00-1.03 (SD $=0.02-0.12$ ). It suggests that alternative OMR and manual procedures both provide a very precise and error-free test checking and analysis. However, the standard deviation of $0.03-$ 0.02 in the alternative OMR process of checking and item analyzing, respectively, and the standard deviation of $0.13-0.12$ in the manual process of checking and item analyzing both give a consistent difference in how "very accurate" those processes are.

Manual processing of student test results is an aged old process of determining student progress in a particular subject. It is the most important component of classroom assessment, as well as an important element of the implementation of the curriculum. The assessment methods used in the classroom are aligned with curriculum standards [1]. As a result, manual processing is expected to produce accurate data for interpreting student development. Indeed, as shown in the table above, manual procedures allow for extremely precise and error-free test checking and analysis. That alternative OMR procedures provide very precise and error-free test checking and analysis is a welcome event. It clearly demonstrates that alternative OMR is within the standard of classroom assessment method as per DepEd Department Order.

\section{Level of Reliability of Data Output}

The results of the level of reliability of data output using manual and alternative OMR procedures in checking test papers and analyzing are shown in Table 3.

Table 3. Level of reliability of using manual vis-à-vis alternative OMR procedure in checking test papers and analyzing its results

\begin{tabular}{|l|l|l|l|l|}
\hline \multirow{2}{*}{ Activity } & Procedure & Mean & $\begin{array}{l}\text { Std. } \\
\text { Dev. }\end{array}$ & $\begin{array}{l}\text { Descriptive } \\
\text { Interpretation }\end{array}$ \\
\hline \multirow{2}{*}{ Checking test papers } & OMR & 1.00 & 0.02 & Very Reliable \\
\cline { 2 - 5 } & Manual & 1.03 & 0.13 & Very Reliable \\
\hline Analyzing results & OMR & 1.00 & 0.02 & Very Reliable \\
\hline
\end{tabular}


International Journal of Theory and Application in Elementary and Secondary School Education (IJTAESE), Vol. 3 (2), 61-75

Effectiveness of Automation in Evaluating Test Results Using EvalBee as an Alternative Optical Mark Recognition

(OMR): A Quantitative-Evaluative Approach from a Philippine Public School

Ronnel P. Cuerdo, Michael Jomar B. Ison, Christian Diols T. Oñate

\begin{tabular}{|l|l|l|l|l|}
\hline & Manual & 1.03 & 0.12 & Very Reliable \\
\hline
\end{tabular}

Legend: 1.00 - 1.49 (1 min or less) = Very Reliable

$1.50-2.49$ (2 mins) = Reliable

$2.50-3.49$ (3 mins) = Moderately Reliable

$3.50-4.49$ (4 mins) = Somewhat Unreliable

4.50 - 5.00 (more than 5 mins) = Unreliable

As revealed in Table 3, both the alternative OMR and manual procedures produce very reliable results in checking test papers with a closer mean score of 1.00-1.03 (SD = 0.02-0.13). Also, both the alternative OMR and manual procedures produce very reliable results in analyzing test papers with a closer mean score of 1.00-1.03 (SD = $0.02-0.12$ ). It denotes that alternative OMR and manual procedures both provide a very dependable and consistent checking and analysis of the test. However, the standard deviations of $0.02-0.02$ in the alternative OMR process of checking and item analyzing and 0.13-0.12 in the manual process of checking and item analyzing show a constant difference in how "very reliable" those procedures are.

Manually processing student test results is a time-honored method of determining a student's progress in a subject. It is the most important aspect of classroom evaluation and a crucial component of curriculum implementation. Curriculum standards are followed when assessing students in the classroom [1]. As a result, manual processing should yield reliable or consistent data for analyzing student growth. The manual process of a student test result, as illustrated in the table above, enables exceptionally reliable and consistent free test checking and analysis. To be as reliable as the manual process qualifies alternative OMR process to provide the necessary tool in the classroom evaluation. It clearly proves that alternative OMR meets the Department Order's criterion of the classroom assessment method.

The result of the test of significant difference on the level of efficiency between manual and alternative OMR procedures in checking and analyzing test results is shown in Table 4.

Table 4. Level of efficiency of using manual vis-à-vis alternative OMR procedure in checking test papers and analyzing its results

\begin{tabular}{|c|c|c|c|c|c|c|c|}
\hline Activity & Procedure & Mean & $\begin{array}{c}\text { Mean } \\
\text { Difference }\end{array}$ & df & t-value & Cohen's d & $\begin{array}{c}\text { Effect } \\
\text { Size }\end{array}$ \\
\hline $\begin{array}{c}\text { Checking } \\
\text { test papers }\end{array}$ & OMR & 1.05 & 3.71 & 48 & $24.607^{* *}$ & 7.00 & Large \\
\hline \multirow{2}{*}{$\begin{array}{c}\text { Analyzing } \\
\text { results }\end{array}$} & OMR & 4.76 & & & & & \\
\cline { 2 - 8 } & Manual & 4.05 & 3.71 & 48 & $24.645^{* *}$ & 7.00 & Large \\
\hline
\end{tabular}

Cohen's d: 0.20 (Small); 0.50 (Medium); 0.80 and above (Large)

**Significant at 01 level of significance

As presented in Table 4, there is a significant difference between the mean evaluation of alternative OMR and Manual procedures in terms of their level of efficiency in checking test papers and analyzing their results. The figures in the table suggest that alternative OMR and manual procedures differ by 3.71 points in favor of the alternative OMR. This mean difference is statistically significant when tested at .01 level, which produces a Cohen's d value of 7.00 that signifies a large effect size. It can be inferred from Table 4 that alternative OMR is a more efficient procedure for checking and analyzing tests compared to the manual process. According to Virtus (2019), efficiency is the most evident benefit of employing optical mark recognition technology to acquire data from papers. In alternative OMR, documents are scanned and typed at a rate that is several times faster than a human can [7]. 
International Journal of Theory and Application in Elementary and Secondary School Education (IJTAESE), Vol. 3 (2), 61-75

Effectiveness of Automation in Evaluating Test Results Using EvalBee as an Alternative Optical Mark Recognition

(OMR): A Quantitative-Evaluative Approach from a Philippine Public School

Ronnel P. Cuerdo, Michael Jomar B. Ison, Christian Diols T. Oñate

The data shows that using an alternative OMR provides a quick assessment of a student's test results. Teachers, in fact, find it useful, especially in terms of its ability to compute for item analysis, which was previously a time-consuming operation. Data on the results will almost always be readily and promptly available. In the absence of an alternative OMR, each document must be painstakingly checked manually before being properly entered into a form or computer system. Although skilled individuals could become proficient with evaluating and inputting data from forms, there seems to be a real limit towards how quickly an individual could do the task [7].

Table 5 reveals the test of significant difference on the level of accuracy between manual and alternative OMR procedures in checking and analyzing test results.

Table 5. Level of the accuracy of using manual vis-à-vis alternative OMR procedure in checking test papers and analyzing its results

\begin{tabular}{|c|c|c|c|c|c|}
\hline \multirow{2}{*}{ Activity } & Procedure & Mean & $\begin{array}{c}\text { Mean } \\
\text { Difference }\end{array}$ & df & $\begin{array}{c}\text { t- } \\
\text { value }\end{array}$ \\
\hline $\begin{array}{c}\text { Checking } \\
\text { test papers }\end{array}$ & OMR & 1.01 & 0.02 & 48 & 0.913 \\
\hline \multirow{2}{*}{$\begin{array}{c}\text { Analyzing } \\
\text { results }\end{array}$} & Manual & 1.03 & & & \\
\cline { 2 - 6 } & OMR & 1.00 & 0.03 & 48 & 1.109 \\
\hline
\end{tabular}

Based on the results in Table 5, there is no significant difference between the level of accuracy of using manual vis-à-vis alternative OMR procedure in checking test papers and analyzing its results $[\mathrm{t}(48)=.913$; $\mathrm{t}(48)=1.109 ; \mathrm{p}>.05)]$. This result means that the two procedures showed a comparable level of accuracy when they were evaluated by the 25 teachers who served as the respondents of the study. In fact, they are both evaluated as "very accurate".

In Virtus's (2019) study, the discrepancy between the OMR machine's mean summary of figures and the teacher's calculated summary of figures was low when student test results were manually processed. This demonstrates that there is just a small difference between the two outcomes, demonstrating the OMR machines' accuracy and reliability. However, this study demonstrates that there is no significant difference between the level of accuracy of using manual vis-à-vis alternative OMR procedures in checking test papers and analyzing their results. It can be deduced from the foregoing that the difference comes from manual processing variation and does not affect the accuracy of the OMR or the alternative OMR process. When comparing the OMR average summary of statistics with the teachers' computed summary of statistics, both studies and the table before demonstrate that both approaches can produce valid data.

There is, however, a finite limit towards how quickly a human individual can actually read and transmit data from student test results, as well as an upper limit to how accurately he can do so. Anyone who has ever had a task that required them to glance at a document, then perhaps a computer monitor, and afterward returns to the document realizes exactly easy it is to forget the sense of their location. It's all too easy to transpose, duplicate data, and so on during this procedure, or just miss-enter data as the teacher becomes fatigued. OMR enhances data collection accuracy by reducing these errors [2].

Table 6 the test of significant difference in the level of reliability between manual and alternative OMR procedures in checking and analyzing test results. 
International Journal of Theory and Application in Elementary and Secondary School Education (IJTAESE), Vol. 3 (2), 61-75 Effectiveness of Automation in Evaluating Test Results Using EvalBee as an Alternative Optical Mark Recognition (OMR): A Quantitative-Evaluative Approach from a Philippine Public School Ronnel P. Cuerdo, Michael Jomar B. Ison, Christian Diols T. Oñate

Table 6. Level of reliability of using manual vis-à-vis alternative OMR procedure in checking test papers and analyzing its results

\begin{tabular}{|c|c|c|c|c|c|}
\hline Activity & Procedure & Mean & $\begin{array}{c}\text { Mean } \\
\text { Difference }\end{array}$ & df & $\begin{array}{c}\text { t- } \\
\text { value }\end{array}$ \\
\hline $\begin{array}{c}\text { Checking } \\
\text { test papers }\end{array}$ & OMn & 1.01 & 0.02 & 48 & 0.825 \\
\hline $\begin{array}{c}\text { Analyzing } \\
\text { results }\end{array}$ & OMR & 1.03 & & & \\
\cline { 2 - 6 } & Manual & 1.00 & 0.03 & 48 & 1.107 \\
\hline
\end{tabular}

As described in Table 6, there is no significant difference between the level of reliability of using manual vis-à-vis alternative OMR procedure in checking test papers and analyzing its results $[\mathrm{t}(48)=.825 ; \mathrm{t}(48)=$ 1.107; $\mathrm{p}>.05)$ ]. This result means that the two procedures showed a similar level of reliability when they were evaluated by the 25 teachers who served as the respondents of the study. In fact, they are both evaluated as "very reliable".

When student test results are manually processed, there is little discrepancy between the OMR machine's average summary of statistics and the teacher's computed summary of statistics, according to Virtus' (2019) research. This illustrates that the discrepancy between the results is quite small, confirming the alternative OMR's accuracy and reliability. However, this study found no statistically significant difference in the level of accuracy of using manual versus alternative OMR procedures in checking test papers and analyzing their results. From the foregoing, it can be deduced that the slight or minimal difference in results from those studies with respect to manual processing variation has no bearing on the reliability of OMR or alternative OMR processes. Both studies show that when the OMR average summary of statistics and the teachers' computed summary of statistics are compared, both methodologies can provide reliable data.

Manually processing student test data, as previously noted, is a time-honored technique of determining a student's progress in a subject. It is the most significant piece of classroom evaluation, and it is also a critical part of curriculum implementation. Curriculum standards are followed when assessing students in the classroom [1]. Alternative OMR processes qualify to give the necessary tool in the classroom evaluation since they are as accurate and dependable as the manual procedure. It demonstrates that alternative OMR fits the Department Order's classroom assessment method standards.

Moreover, alternative OMR technology reduces the number of persons or labor hours necessary to process student test results by automating the most labor-intensive operation in assessment evaluation. By reducing the number of teachers or the amount of time it takes to process student test results, alternative OMR technology decreases the overall expense of processing student test results. Furthermore, a human's ability to actually examine and transmit data from student test results is limited, as is his ability to do so accurately. Anyone who has ever had a task that needed them to glance at a document, then a computer monitor, then back to the document realizes just easy it is to lose track of their information. It's all too simple for a tired teacher to invert, duplicate, or just erroneously input data. Alternative OMR enhances data collection accuracy by reducing these errors.

\section{CONCLUSION}

The following conclusions were drawn based on the indicated findings:

1. There is a clear and significant difference between manual process and alternative OMR process as regards efficiency or the ability to do something with the least amount of time, resources, and effort or performance expended. In fact, the difference is very large indeed in favour of alternative OMR. 
International Journal of Theory and Application in Elementary and Secondary School Education (IJTAESE), Vol. 3 (2), 61-75

Effectiveness of Automation in Evaluating Test Results Using EvalBee as an Alternative Optical Mark Recognition

(OMR): A Quantitative-Evaluative Approach from a Philippine Public School

Ronnel P. Cuerdo, Michael Jomar B. Ison, Christian Diols T. Oñate

The null hypothesis, which specifically states that no significant difference between the level of efficiency using manual and alternative OMR procedures, therefore, is set aside.

2. There is no significant difference between manual process and alternative OMR process as regards accuracy. It means the quality standards of accuracy are not going to suffer had alternative OMR been used in checking and item analyzing student test results. The null hypothesis, which specifically states that no significant difference between the level of accuracy using manual and alternative OMR procedures, therefore, is affirmed.

3. There is no significant difference between manual process and alternative OMR process as regards reliability. It means the data reliability of alternative OMR is on par with the standards used in checking and item analyzing student test results. The null hypothesis, which specifically states that no significant difference between the level of reliability using manual and alternative OMR procedures, therefore, is hereby affirmed.

Despite the fact that alternative OMR can be obtained for almost nothing, the efficiency, accuracy, and reliability of checking and item analysis have not suffered. In fact, according to the opinions of the teacherrespondents themselves and the findings of this research, alternative OMR is very effective as most of the variables in determining effectiveness have been met or, even better, have surpassed expectations.

This study unequivocally demonstrated the effectiveness of alternative OMR in evaluating test results. Thus, the following recommendations are hereby presented:

1. Since the effectiveness of alternative OMR in evaluating test results has been demonstrated, teachers may opt to employ this method as part of their standard method of checking and item analyzing student test results. It could have relieved them of the burden of one of the most tedious and repetitive tasks that a teacher can have.

2. Teachers may opt to take the initiative in automating some, if not all, of the processes of delivery, implementation, and assessment of the educational process as a whole, thereby equipping themselves with 21st-century skills in the process and becoming an active participants in relieving themselves of the burden of clerical work.

3. Department of Education administrators may encourage the use of alternative OMR in evaluating test results not only to continuously improve public education but also to relieve teachers of the burden of clerical work.

4. Administrators at the Department of Education may develop a program that includes EvalBee as one of the software applications to be studied in order to equip educators with 21st-century skills.

5. Tertiary-level instructors, professors, and researchers may subject the EvalBee application to see whether it fits the peculiar needs of their institution.

\section{Scope and Limitations of the Study}

This study, like any other, has limitations. These restrictions, on the other hand, may pave the way for new research. The data collected through quantitative- evaluative survey questionnaires were limited to specific respondents, which were twenty-five (25) teachers at various levels. Every teacher has evaluated (checking and item analysis) twenty (20) student test results using alternative OMR and manual processing.

The distinctive characteristic of the school at which the data has been collected is a secondary public school only. No data was collected from elementary and tertiary levels and/or the equivalent levels in private schools. And lastly, this research has evaluated a single Android OMR smartphone application called Evalbee offered for free by Ekodroid Labs. The researcher did not include other OMR smartphone applications available on Android, Windows, the iPhone Operating System, and other platforms. 
International Journal of Theory and Application in Elementary and Secondary School Education (IJTAESE), Vol. 3 (2), 61-75

Effectiveness of Automation in Evaluating Test Results Using EvalBee as an Alternative Optical Mark Recognition

(OMR): A Quantitative-Evaluative Approach from a Philippine Public School

Ronnel P. Cuerdo, Michael Jomar B. Ison, Christian Diols T. Oñate

As a result, more research is needed to evaluate and validate the findings of this study in the additional classifications indicated above.

\section{REFERENCES}

Department of Education. (2015). D. 0. 8, s. 2015 Policy Guidelines on Classroom Assessment for the K to 12 Basic Education Program

Orobor, I. (2015). A Novel Framework for Student Result Computation as a Cloud Computing Service. American Journal of Systems and Software. 1.13-19.10.12691/ajss-3-1-2.

Jacobson, D. (2016). Causes and Effects of Teacher Burnout. Walden University Scholar Works. Walden Dissertations and Doctoral Studies Collection

Technopedia, Inc. (2020). Automation. Techopedia - Janalta Interactive Inc. https://www.techopedia.com/definition/3 2099/automation

Department of Education. (2016). D.0. 55, s. 2016. Policy Guidelines on the National Assessment of Student Learning for the K to 12 Basic Education Program.

Fabella, J.P. (2016). Santa Rosa City obtains Optical Mark Reader (OMR) Scanners. DepEdCalabarzon. https://depedcalabarzon.ph/2016/08/santa-rosa-city-obtains-optical-mark-reader- omr-scanners/

Virtus, L. M. (2019). Performance Mapping of Optical Mark Recognition (OMR) Machines in The Division of Batangas City: Basis for Program Enhancement. International Journal of Advanced Research and Publications Volume 3 - Issue 9, September 2019 Edition ISSN:2456-9992

Catalan, J. A. (2017). A framework for automated multiple-choice exam scoring with digital image and assorted processing using readily available software. Manila: De La Salle University.

Patel, N.V and Prajapati, G.I. (2015). Various Techniques for Assessment of OMR Sheets through Ordinary 2D Scanner: A Survey. International Journal of Engineering Research \& Technology (IJERT) Vol. 4 Issue. ISSN (Online): 2278-0181

Tavana, A., Abbasi, M., and Yousefi, A. (2016). Optimizing the correction of MCQ test answer sheets using digital image processing. 2016 Eighth International Conference on Information and Knowledge Technology (IKT), Hamedan, pp. 139-143. https://doi: 10.1109/IKT.2016.7777754.

Kakade, N. and Jaiswal, R. C. (2017). OMR Sheet Evaluation Using Image Processing. JETER (ISSN-23495162) VOLUME 4, ISSUE 12

Karunanayake, N., (2015), OMR Sheet Evaluation by Web Camera Using Template Matching Approach. International Journal for Research in Emerging Science and Technology. VOLUME-2, ISSUE-8. E- ISSN: 23497610

Statista. (2021). Number of smartphone users in the Philippines from 2015 to 2019 with a forecast until2025. https://www.statista.com/statistics/46718 6/forecast-of-smartphone-users-in-the- Philippines/

Ekodroid Labs. (2021) EvalBee - (Free OMR Answer sheet scanner).

https://play.google.com/store/apps/details?id=com.ekodroid.omrevaluator\&hl=en\& gl=US

Spencer, Thompson. (2016). Worker Cooperatives in the Theory of the Firm: Marx and Veblen on Technological Determinism, Journal of Economic Issues, 50:4, 913-939, DOI:10.1080/00213624.2016.1249743

Matthewman, Steve. (2011). Theorizing Technology. Palgrave Macmillan. ISBN 978-0-230-34395-5 (eBook)

Shields, M.A. (2012). Review of Technology and Social Theory. Technology and Culture 53(4), $\quad$ 918920. doi:10.1353/tech.2012.0130. 
International Journal of Theory and Application in Elementary and Secondary School Education (IJTAESE), Vol. 3 (2), 61-75

Effectiveness of Automation in Evaluating Test Results Using EvalBee as an Alternative Optical Mark Recognition

(OMR): A Quantitative-Evaluative Approach from a Philippine Public School

Ronnel P. Cuerdo, Michael Jomar B. Ison, Christian Diols T. Oñate

McLennan, S. (2015). Techno-optimism or Information Imperialism: Paradoxes in Online Networking, Social Media and Development. Information Technology for Development.

22. 10.1080/02681102.2015.1044490.

Vydra S., and Klievink B. (2019). Techno- optimism and policy-pessimism in the public sector big data debate. Government Information Quarterly, Volume 36, Issue 4, IS SN 0740-624X

Nurwahida, F. T., Jayasuriya, D. P., Xiang, L. W. and Mazharet, S. F. (2017). Clerical Work for School Teachers: A Burden or A Responsibility? Journal of Humanities, Language, Culture and Business (HLCB)Vol. 1: no. 3 (2017) page 26-36 | www.icohlcb.com | eISSN : 01268147 Cabigas, L. (2019). Who Let the Teachers Out:

Exploring the Main Factors which Contribute to Teacher Attrition in Philippine Schools. Monash University https://www.academia.edu/

Jacobson, D. (2016). Causes and Effects of Teacher Burnout. Walden University Scholar Works. Walden Dissertations and Doctoral Studies Collection https://scholarworks.waldenu.edu/cgi/vie wcontent.cgi?article $=3938 \&$ context=diss ertations.

Oke, A.O., Ajagbe, M.A., Ogbari, M.E. \& Adeyeye, J.O. (2015). Teacher Retention and Attrition: A Review of the Literature. Mediterranean Journal of Social Sciences Vol 7 No 2 S1 March 2016. ISSN 2039- 2117

David, C., Albert, J. R. and Vizmanos, J. F. (2019). Pressures on public school teachers and implications on quality. Policy Notes. Philippine Institute of Development studies. ISSN 2508-0865 (electronic) No. 201901

Philippine Institute for Developmental Studies. (2015). Teachers and Our State of Education. https://pids.gov.ph/pids-in- the-news/1359

Department of Education. (2018). Statement on DepEd's review of teachers' workload. https://www.deped.gov.ph/2018/09/04/st statement-on-depends-review-of-teachers- workload/

De Witte, L. (2019). Global Challenges in Assistive Technology. Special Issue: AAATE 2019 Conference - Global Challenges in Assistive Technology: Research, Policy \& Practice. Supplement Issue of Technology and Disability (Volume 31, issue s1). ISSN 1055- 4181/19

Li, M. and Wong, K. (2018). Rain Classroom: Bridging the Gap Between Teachers and Learners. International Journal of Mobile and Blended Learning (ISSN: 1941- 8647).

Capunitan P.M., Alinsod A.A., and Palanas D.M. (2019). Digital assessment: empowering 21st century teachers in analyzing student's performance in Calamba City. JPAIR Institutional Research Vol. 13 No. 1 (2019)

Department of Education. (2012). D.0. 40, s. 2012. DepEd Child Protection Policy.

Department of Education. (2016). D.0. 55, s. 2016. Policy Guidelines on the National Assessment of Student Learning for the K to 12 Basic Education Program.

Patoule, S., Pawar, A., Patel, A., Panchal, A., and Joshi, R. (2016). Automatic system for grading multiplechoice questions and feedback analysis. International Journal of Research and Applications, Special Issue 39, pp. 16-19, Mar. e-ISSN: 2320-8163 